\title{
On the Role of Bubbles in Metallic Splat Nanopores and Adhesion
}

\author{
Meng Qu and Andrew Gouldstone
}

(Submitted February 20, 2008; in revised form April 22, 2008)

\begin{abstract}
Highly nanoporous surfaces were observed on the underside of Ni splats. Experiments varying process parameters and substrate treatments were performed to determine the mechanism of pore formation. A theory of impact-induced bubble nucleation and freezing into pores is presented, and calculations are compared with experimental results. Pore formation and morphology is strongly dependent on substrate (a) thermal properties as they affect time for bubble growth before solidification into pores and (b) roughness as submicron scratches enhance nucleation by providing heterogeneous sites and several micron grooves reduce the driving force for nucleation. Splat pull-off experiments are shown that suggest bubble nucleation and pore formation strongly affect adhesion, and represent a strong contribution to the effectiveness of surface roughening. Finally, this observation shows the potential for the manufacturing of high-surface area materials using thermal spray.
\end{abstract}

Keywords porosity of coatings, roughness effects, splats

\section{Introduction}

Splat formation is considered a highly nonequilibrium process, due to the associated rapid cooling (rates have been reported approaching $\left.10^{8}{ }^{\circ} \mathrm{C} / \mathrm{s}\right)($ Ref 1,2$)$, spreading, and solidification ( $\operatorname{Ref} 3,4)$. In recent years, the study of single splat morphology and microstructure has greatly expanded, in no small part due to the increasing availability of computational power and high-speed photography. Perhaps most notable is the work by Moreau et al. in which transparent substrates were used to examine splatsubstrate interaction in situ at high frame rates (Ref 5). Resolution, however, is limited to optical. In addition, computational modeling of splat impact has steadily improved, incorporating physical properties relevant to droplet spreading and splat solidification (Ref 6, 7). Subsequent morphological (shape) observations have reasonably matched those of experiments and provided insight into the role of nontrivial phenomena such as splat curling (Ref 8), fragmentation, and breakup (Ref 4). Foci of such studies have not only been the modeling of single splat impact and solidification, but also the relation to such actions on overall coating architecture, in particular the wide variety of pores in the coatings (Ref 9 ). These pores range in size and aspect ratio from highly elongated (and rather ubiquitous) interlamellar 'cracks' down to nanoscale

Meng Qu, Center for Thermal Spray Research, Stony Brook University, Stony Brook, NY 11794-2275; and Andrew Gouldstone, Department of Mechanical and Industrial Engineering, Northeastern University, Boston, MA 02115. Contact e-mail: bubbleraft@gmail.com. (tens to hundreds of nanometer) quasi-spherical pores. The latter have been viewed somewhat in high resolution cross section (Ref 10), and can also be inferred from small angle neutron scattering (SANS) experiments (Ref 11).

These nanopores (in the nanoporosity community, the term 'micropores' refers to a far smaller size scale (Ref 12)) represent an important study in the field of thermal spray (TS), especially as the process technology moves from 'band aid' to 'prime reliant' and more chemically or electronically functional coatings. Their size and potential universal distribution in coatings affect property and transport models in that they cannot be treated as a composite feature, but actually change the properties of the intrinsic material itself (a la nanocomposites (Ref 13)). In addition, when considering the contribution of such a small scale defect to overall material behavior, continuum methods may not be accurate. That is to say, considering the role of a pore in transport behavior, overall conductance $C=k(R) * R$, where conductivity $k(R)$ is now a function of dimension itself (Ref 14, 15). The high curvature $(R \approx 10-100 \mathrm{~nm})$ makes these pores highly susceptible to sintering and/or coalescence (Ref 16). Finally, their role in intersplat or splat-substrate adhesion is not understood but could be important. Micro(nano)pore formation in splats is currently attributed to fluid breakup and solidification mechanisms in splats, and models have shown that holes of micron-scale can be made via these mechanisms (Ref 9). However, this does not explain the existence of even smaller pores (shown by SANS). In addition, experimental splat characterization efforts have mainly involved top-down or cross-sectional views; few observations have been made of the splat underside, at least not in high resolution. Recently, we showed such observations on Ni splats, revealing a highly nanoporous surface (Ref 17). This was attributed to a high rate of supersaturated gas bubble nucleation at the splat/substrate interface, as a result of initial impact pressure $(\approx 1 \mathrm{GPa})$ 
and rapid depressurization within 100 ns. Experimental results compared favorably with analytical models of gas bubble nucleation in the geology literature (Ref 18, 19).

In addition to the surface architecture, one interesting aspect of the Ni splats in the aforementioned study was the relative ease with which they were pulled off the substrate. In TS, adhesion of coatings is paramount; a number of macroscopic tests have been devised to measure pull-off strength (ASTM) and different methods have been proposed to improve this value ( Ref 20). One preprocessing technique that has been used for decades is grit blasting, the theory behind which is that the roughening imposed on the substrate increases bond strength via 'mechanical interlocking.' Unfortunately, this has never been proven, and although a wealth of experimental evidence has shown that grit-blasting works quite well (i.e., coatings sprayed on flat, polished surfaces do not stick while those on roughened surfaces successfully adhere), few models exist that attempt to account for the large difference in adhesion imparted by the roughness, which is typically of order of up to $5 \mu \mathrm{m}$ (an exception is work by Liu et al. (Ref 9)). An additional complication is the lack of confidence in typical TS pull-off tests, which are highly dependent upon specimen preparation, and often reflect coating cohesion (Ref 20). Thus, debate still exists as to the origin of improved adhesion, that is to say, does surface roughening affect the mechanical loading on the substrate level, or the intrinsic bonding on the splat level?

In this study, we systematically studied the system of $\mathrm{Ni}$ splats on SS substrates, for a number of process conditions, and examined the resulting porosity. We compared experimental observations to bubble nucleation theories in the geology literature, and showed how surface conditions can affect bubble/pore morphology. Finally, we performed a simple comparison of splat-substrate adhesion for different process conditions. Substrates were roughened to different degrees using sandpaper, and relative splat adhesion was assessed using a statistical method (see "Methods" section). At the outset, we hypothesized that the splats on rougher surfaces would exhibit (i) less nanopores on the underside and as a result (ii) improved bonding. The fundamental assertion behind this is that roughness of sufficient magnitude to divert the flow of liquid would significantly reduce the initial impact pressure and depressurization rate, suppressing bubble nucleation at the splat/substrate interface thus providing a greater surface area for splat/substrate interdiffusion. Results supported this hypothesis, and suggest an additional important consideration in the effect of substrate grit blasting in TS.

\section{Materials and Methods}

\subsection{Splat Deposition}

Commercially pure nickel splats were deposited on stainless steel (type 304) and copper substrates using atmospheric plasma spray (APS). Average starting powder size was $42 \mu \mathrm{m}$. These splats were made with a $7 \mathrm{MB}$ APS Torch (Sulzer Metco, Inc., Westbury, NY) using ArH2 plasma gas flow. DPV 2000 (Tecnar Automation Ltd., Quebec) was used to measure average particle temperature $\left(\sim 2500^{\circ} \mathrm{C}\right)$ and velocity, the latter controlled by varying gas flow and plasma arc current. Most substrates were mirror-polished; in some cases, artificial roughening was imposed with 120 - or 60-grit sandpaper, and roughness was measured via scanning white light interferometry to be 0.6 and $1.3 \mu \mathrm{m}$, respectively. In other cases, isolated scratches were made in the substrate via polishing media. Before deposition, all substrates were acetone cleaned, and then preheated up to $300{ }^{\circ} \mathrm{C}$ to remove adsorbates (Ref 21). Spray parameters and substrate conditions were varied to study the bubble formation and its interaction with substrate (Table 1). Splats were collected by passing the torch $(500 \mathrm{~mm} / \mathrm{s}$ traverse speed) over the polished and/or roughened substrates (acetone cleaned and preheated up to $300{ }^{\circ} \mathrm{C}$ to remove adsorbates) at low powder feed rates $(2-5 \mathrm{~g} / \mathrm{min})$. In addition, Ni splats deposited via vacuum plasma spray (VPS, Plasma Technic PT-F4) with $6 \mathrm{~mm}$ nozzle were removed from polished 304 stainless steel substrates (detailed spray conditions can be found elsewhere (Ref 22)), and the underside examined.

\subsection{Splat Characterization}

After deposition, optical micrographs (Nikon Epiphot 200) were taken of the substrates, and SEM (LEO1550) and scanning white light interferometry (Zygo 200) were performed on selected splats, to examine morphology and any porosity. Following this, some splats were removed with carbon tape (electron microscopy sciences (EMS)), and the underside examined under SEM. In some cases, splats were 'folded' using carbon tape with a slight lateral force, allowing direct comparison of splat and underlying substrate. Adhesion of splats across different substrate conditions was compared in the following manner: Carbon tape was pressed with a $30 \mathrm{~kg}$ weight for an estimated average pressure on a $3 \mathrm{~cm}^{2}$ area of the sprayed region for $10 \mathrm{~s}$, and then pulled off. As we hypothesized that rough surfaces would provide greater adhesion, higher pressures were used, that is to say, splats were pulled 'harder.' Relative adhesion was assessed by recourse to (a) examination

Table 1 Spray parameters for the experiments

\begin{tabular}{|c|c|c|c|c|c|c|c|c|}
\hline $\begin{array}{l}\text { Spray } \\
\text { velocity, } \mathrm{m} / \mathrm{s}\end{array}$ & $\begin{array}{l}\text { Ni particle } \\
\text { size, } \mathbf{m m}\end{array}$ & $\begin{array}{l}\text { Ar flow, } \\
\text { slm }\end{array}$ & $\begin{array}{l}\mathbf{H}_{2} \text { flow, } \\
\text { slm }\end{array}$ & $\begin{array}{c}\text { Carrier gas } \\
\text { flow, slm }\end{array}$ & $\begin{array}{c}\text { Voltage, } \\
\mathbf{V}\end{array}$ & $\begin{array}{c}\text { Current, } \\
\mathbf{A}\end{array}$ & $\begin{array}{l}\text { Torch-substrate } \\
\text { distance, mm }\end{array}$ & $\begin{array}{l}\text { Powder feed } \\
\text { rate, rpm }\end{array}$ \\
\hline 140 & $42 \pm 12$ & 60 & 8 & 4 & 67 & 600 & 130 & 1 \\
\hline 65 & $42 \pm 12$ & 30 & 2 & 3 & 64 & 400 & 130 & 1 \\
\hline
\end{tabular}


of the tape for areal coverage of splats and (b) comparison of 'taped' and 'untaped' regions of the substrate. The tape bond strength was of order MPa (Ref 23), so this provided an upper bound for fracture analyses. Pulled-off splats were examined under HRSEM to search for underside bubbles/pores. Image analysis (UTHSCSA ImageTool) was used to quantify pore size and distribution.

\section{Results and Discussion}

Figure 1 shows SEM images of Ni splat undersides, sprayed with different average velocities (splat top view shown in inset). Splats are disk-shaped, and little splashing has occurred. Under high magnification, a highly porous structure is observed, as reported in Ref 17. Pores are near-hemispherical, and for the most part located at the splat underside. Bubbles are on average smaller in the case with lower velocities. This is consistent with the mechanistic argument that bubbles appear due to the following progress of events: (i) upon splat impact, hydrostatic pressure near the interface reaches up to $1 \mathrm{GPa}$, causing markedly high gas solubility in the liquid droplet, (ii) gas trapped between molten particle and substrate is dissolved in near-interface regions, (iii) rapid ( $\approx 100 \mathrm{~ns}$ ) depressurization causes supersaturation and nucleation of bubbles at the splat/substrate interface, and (iv) bubbles move with spreading fluid and are frozen into pores upon solidification. In our original observations, we approximately quantified bubble density using nucleation theories developed in the geologic literature (Ref 18, 19, 24, 25). Figure 2(a) shows a plot of maximum impact pressure $P_{\max }$, and depressurization time $t_{\text {dep }}$ (we define $t_{\text {dep }}$ as the time to decrease to $0.1 P_{\max }$ ), as a function of impact velocity, for molten $\mathrm{Ni}$ droplets at melting temperature. Values were calculated from droplet impact models of $\mathrm{Li}$ and $\mathrm{Li}$ (Ref 26). Melting temperature was used for input values, because in the literature, higher temperature values for such quantities are rare. However, density $\rho$ and viscosity $\mu$ do not change significantly enough to affect the physical arguments presented here. Note that for a flat substrate, not only does maximum impact pressure increase, but also $t_{\text {dep }}$ decreases with increasing particle velocity, both trends providing a higher tendency for gas supersaturation and bubble nucleation. This is seen in Fig. 2(b), which shows maximum bubble nucleation rate $J_{\max }$ versus impact velocity, for molten $\mathrm{Ni}$ at its melting temperature $T_{\mathrm{m}}$, as calculated from equations derived by Toramaru (Ref 18, 19). Therefore, the experimental results are expected from the equations, and match within an order of magnitude, providing support for the proposed mechanism.

Final pore structure is dependent not only on bubble nucleation, but also on bubble growth and motion (Ref 18, 24-26) before solidification. Thus, it is reasonable to expect that if cooling and solidification are faster due to
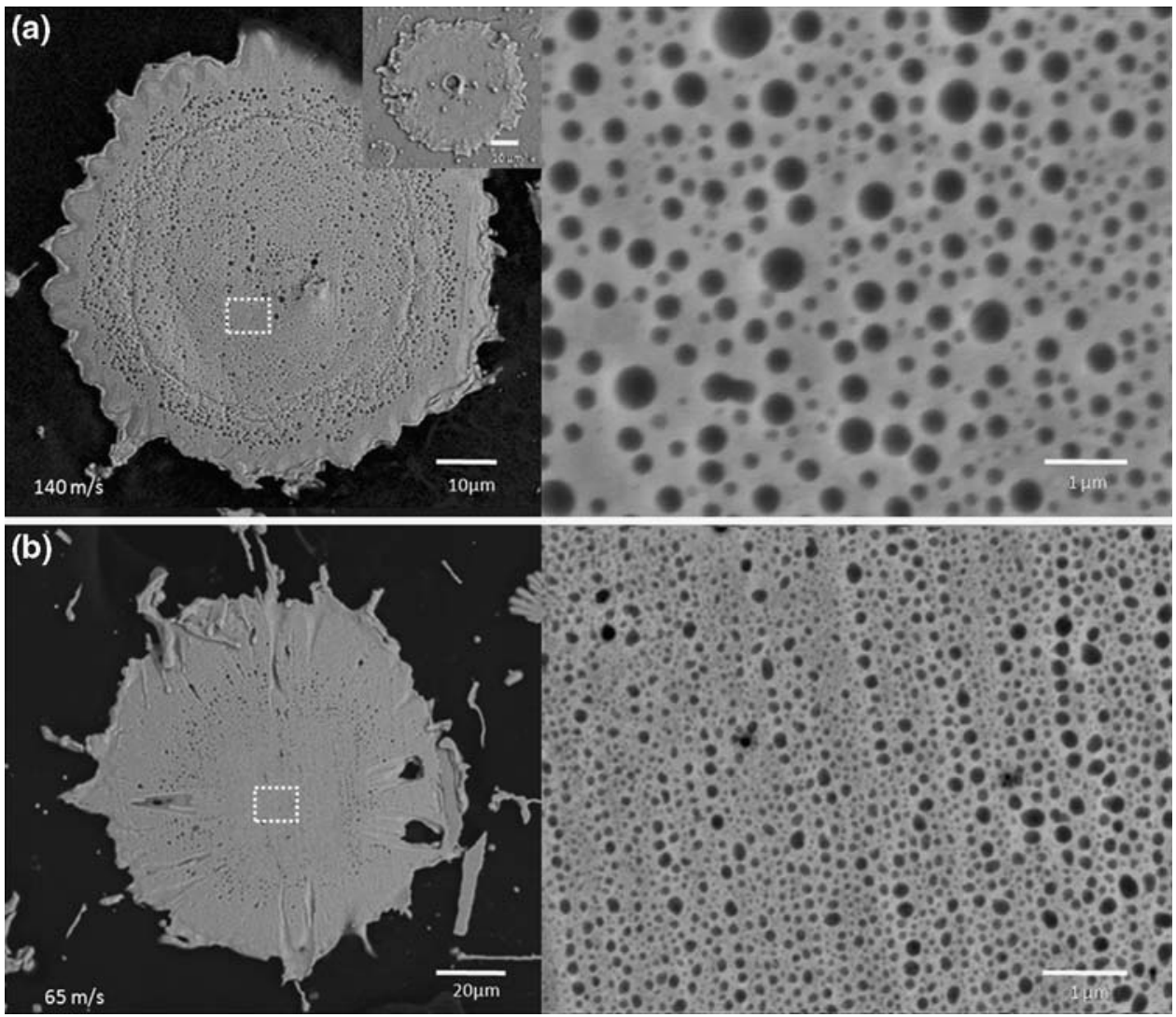

Fig. 1 Ni splats on polished SS substrates, impacted at (a) $140 \mathrm{~m} / \mathrm{s}$ and (b) $65 \mathrm{~m} / \mathrm{s}$ 

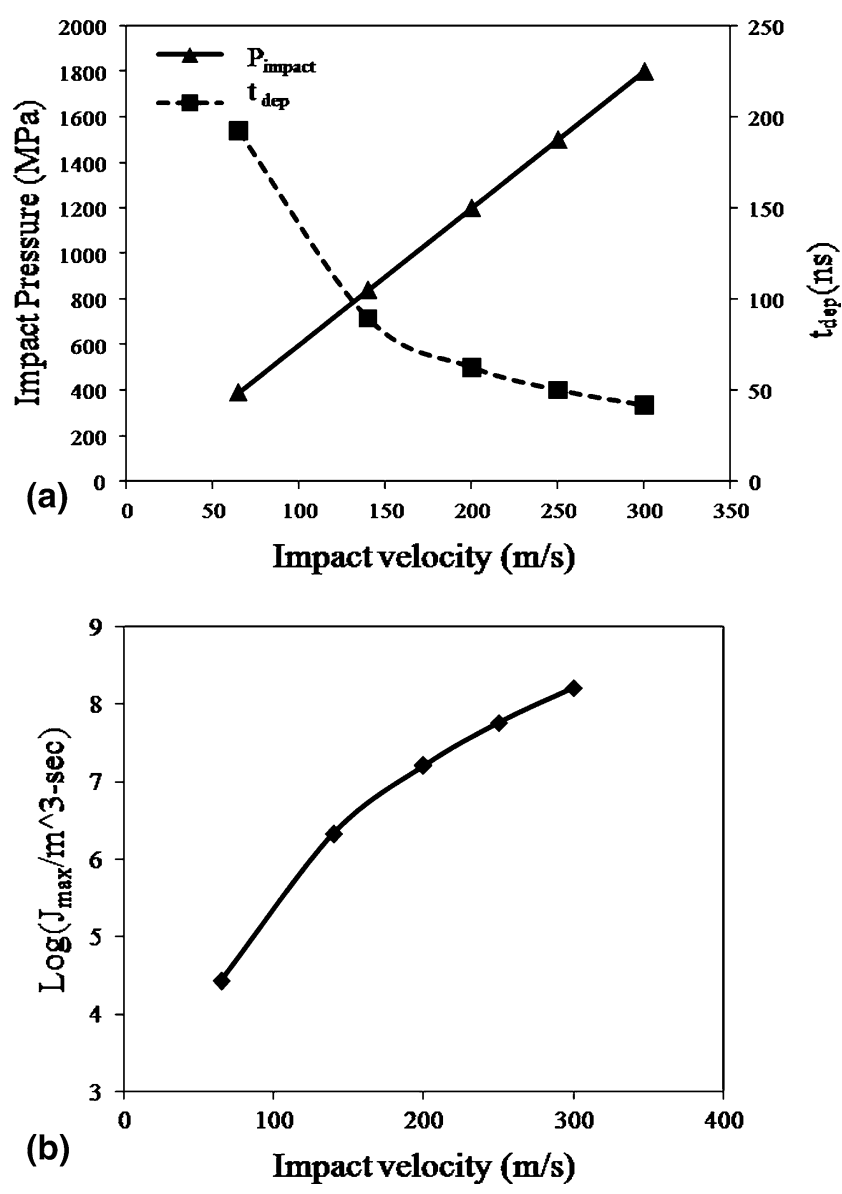

Fig. 2 Plots of (a) $P_{\max }, t_{\text {dep }}$ and (b) $J_{\max }$ versus velocity

the substrate, bubble/pore morphology would be affected. We demonstrated this visually in our initial observations (Ref 17), in which the underside of a $\mathrm{Ni}$ splat on a $\mathrm{Cu}$ substrate displayed not only decreased average pore size, but also in some cases evidence (elongated bubbles) that solidification occurred quickly enough to freeze bubbles during liquid spreading. Figure 3(a) shows a high magnification image of elongated bubbles, with splat liquid flow direction, and Fig. 3(b) shows the distribution of pores in $\mathrm{Ni}$ splats sprayed under identical conditions for $\mathrm{SS}$ and $\mathrm{Cu}$ substrates. Note that the $\mathrm{Cu}$ substrate produces a lower mean value and tighter distribution of pore size that we attribute to faster cooling and solidification of the splat. This is in turn due to the higher thermal conductivity of $\mathrm{Cu}(\operatorname{Ref} 27)$.

Figure 4 shows a direct comparison of splat and substrate, accomplished via folding of the splat with carbon tape. A few important observations can be made. First, the splat pattern is reflected in the steel substrate (Fig. 4c). That is to say, impressions of bubbles were frozen into the steel as pores. This is not particularly surprising, given the pressure necessary to sustain such a small bubble in the Ni. The fundamental equation relating bubble pressure $p$ to radius $R$ ( $\operatorname{Ref} 25)$ is
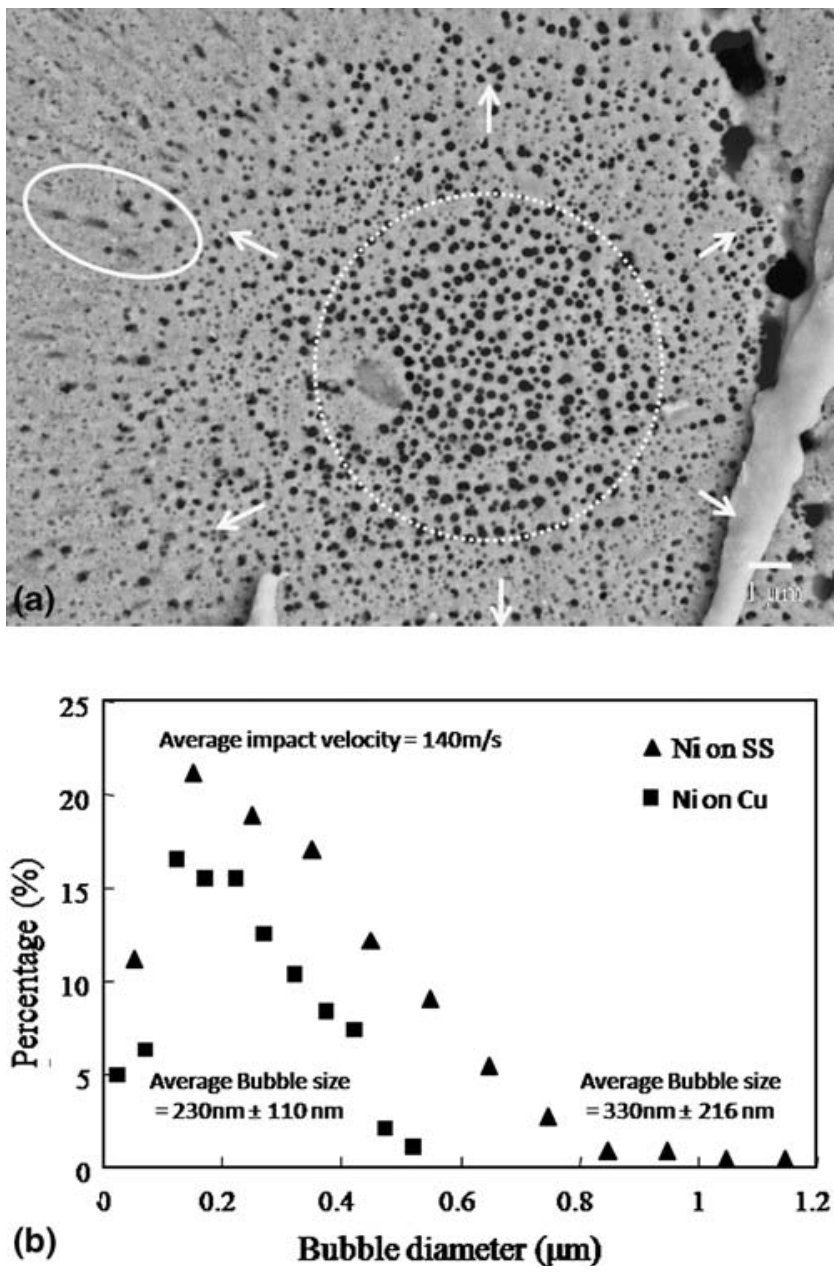

Fig. 3 (a) Ni splat on $\mathrm{Cu}$ substrate and (b) bubble distribution histograms

$$
p=4 \gamma / R,
$$

in which $\gamma$ is surface tension of the gas/liquid interface. According to our calculations, for $\mathrm{Ni}$ at melting temperature $\left(1450{ }^{\circ} \mathrm{C}\right)$ and $2000{ }^{\circ} \mathrm{C}$, this value is $1.9 \mathrm{~N} / \mathrm{m}$ (Ref 28 ) and $1.2 \mathrm{~N} / \mathrm{m}$ (Ref 29), respectively; so, for a bubble of $R=40 \mathrm{~nm}, p=120-200 \mathrm{MPa}$. This local pressure is insufficient to cause local deformation of room temperature steel, especially considering the well-known size effect in metals (Ref 30 ), but due to surface heating a significant amount of local softening is expected. This softening is also illustrated in Fig. 4(b) and (c), which clearly shows lateral fluid-like deformation (marked with white arrows) of the substrate at the edge of the Ni splat. Whether this is indeed softening or substrate melting cannot be seen from the images. Solidification models (Ref 31) have predicted that Ni would not cause melting in SS, but that conclusion was drawn from a critical cut-off thickness of melted surface layer. Further work is needed to examine the role that a molten or softened substrate layer may play in the mobility of bubbles. 

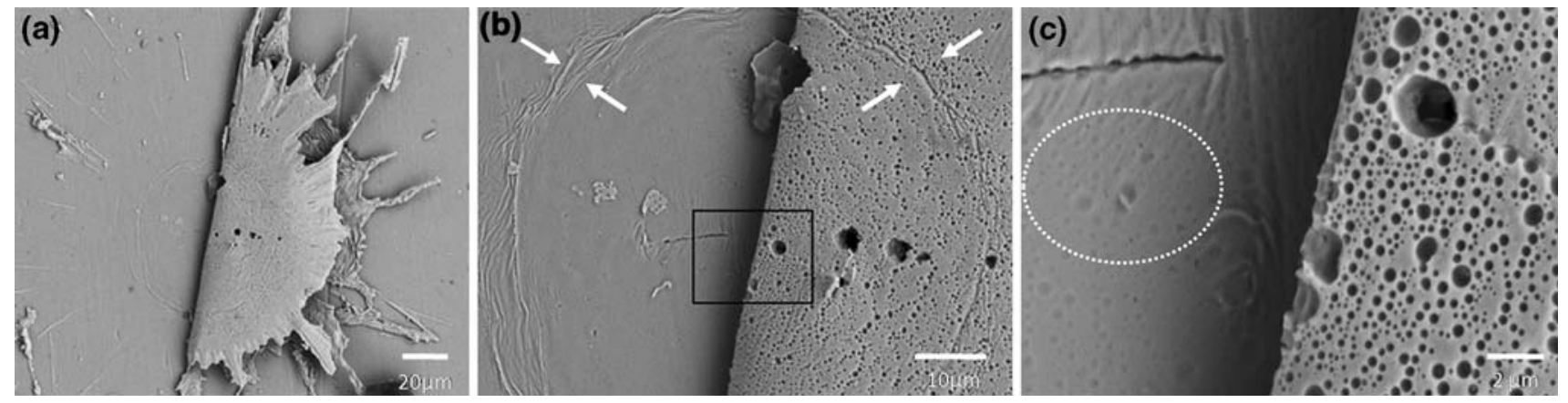

Fig. 4 (a) Folded Ni splat on SS, showing bubbles/pores and relief in substrate in the higher magnifications (b, c)

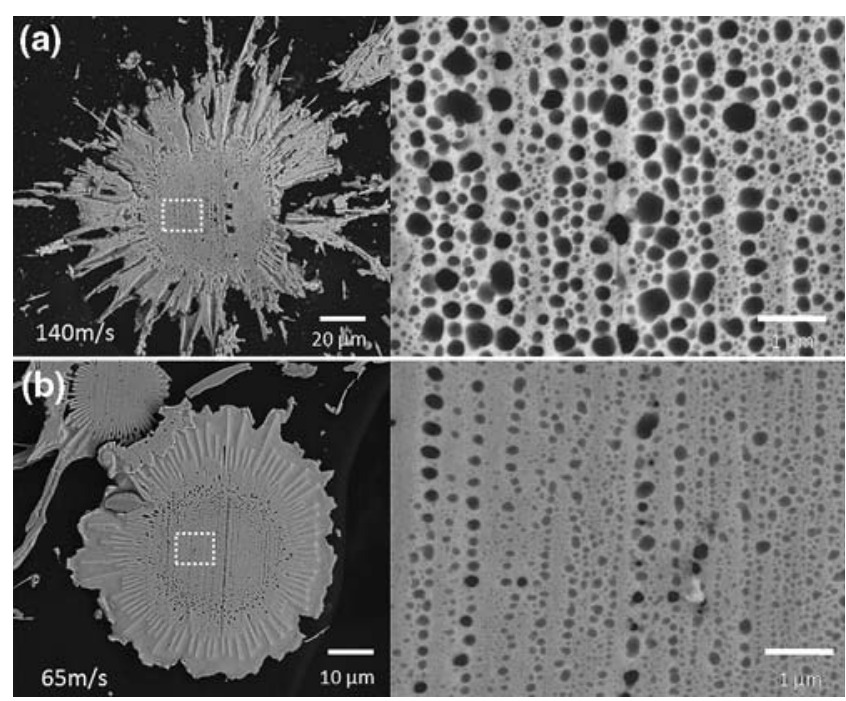

Fig. $5 \mathrm{Ni}$ splats on scratched SS substrates, impacted at (a) $140 \mathrm{~m} / \mathrm{s}$ and (b) $65 \mathrm{~m} / \mathrm{s}$

The driving force behind bubble nucleation is gas supersaturation in the liquid. The kinetics is dictated by surface energy considerations. As in any other nucleation mechanism, provided sufficient driving force exists, surface irregularities will provide a further heterogeneous nucleation site (Ref 32, 33). In this scenario, all nucleation may be considered heterogeneous, as it occurs at the splat/ substrate interface. However, the barrier to nucleation may be reduced via the introduction of small $(\leq 0.2 \mu \mathrm{m})$ roughness on the substrate. This is illustrated in Fig. 5, which shows the underside of a splat that was impacting on a prescratched substrate, at different velocities. Two salient features are observed from the figure. First, pore morphology suggests bubbles have nucleated on the scratches preferentially; as impact velocity (and driving force for nucleation) decreases, bubble density in the flat region decreases but persists on scratches. Second, bubbles are 'lined up,' despite the fluid flow that would tend to push them radially outward from the impact center. This means bubbles (a) are in a sufficiently low energy state to resist detachment from scratches or (b) nucleate late enough such that fluid is relatively stationary. Based on the observations for $\mathrm{Cu}$, in which bubbles have been caught in motion via solidification, it would appear that (a) is dominant, but this requires further study.

As stated above, roughness on the nanoscale would reduce the kinetic barriers to nucleation, provided that driving force in the form of high hydrostatic pressure leading to gas solubility persists. Presumably, this would not be the case if roughness were on the order of particle size. In such a case, as illustrated in Fig. 6, hydrostatic pressure would not reach such a high maximum on impact, as fluid would flow and decelerate upon contact with the surface. Fluid impact modeling in the presence of surface roughness is extremely nontrivial, and the most notable models in the literature (Ref 7, 9, 34) have focused on spreading and solidification; there has been no systematic study on the effect of roughness on initial impact pressure. Nevertheless, qualitative reasoning allows the hypothesis that significant roughness would tend to decrease bubble nucleation and also porosity. This assertion is supported by Fig. 7, which shows SEM images of splats removed from SS substrates of different roughness (see "Materials and Methods") and comparison with Fig. 1. Splats from the polished substrate display a significant level of porosity, and splats from the 120 -grit $(0.6 \mu \mathrm{m}$ roughness) sample, a markedly decreased amount, and for the most part in sharper regions. Splats from the 60 -grit $(1.3 \mu \mathrm{m}$ roughness) sample display very few pores. The decreased amount of porosity is consistent with the argument presented above.

The effect of the above phenomena on adhesion is described here. Figure 8 shows optical magnification images of the three substrates, from which splats have been pulled off, with a horizontal line marking a boundary of the surface exposed to tape. Figure 9 shows Zygo images of single splats on the three substrates. A few salient features arise. First, the splats on the smoother substrates are wider than those on the rougher substrates. This larger flattening ratio is an expected result, as the rough surface hinders molten splat spreading after impact. Second, given the difference in splat sizes, there is no significant difference in deposition areal density among the three cases; that is to say, the same number of splats deposited on all substrates. Finally, however, the taped regions show large differences between the three; for the 


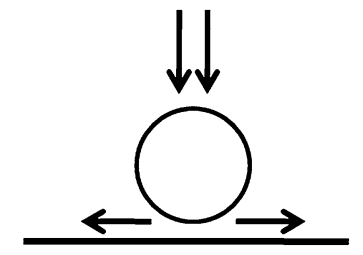

(a)

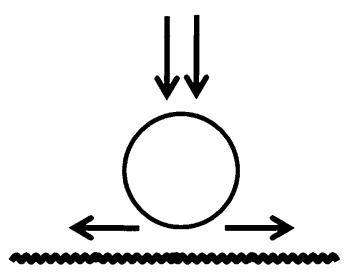

(b)

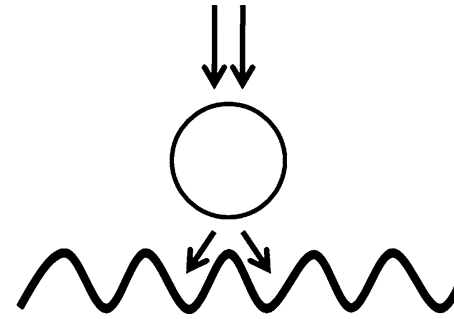

(c)

Fig. 6 Schematic of hydrostatic pressure versus shear flow for impacting droplets on (left) flat surface, (middle) flat surface with nanoscale roughness, and (right) surface with roughness of sufficient order to divert liquid flow
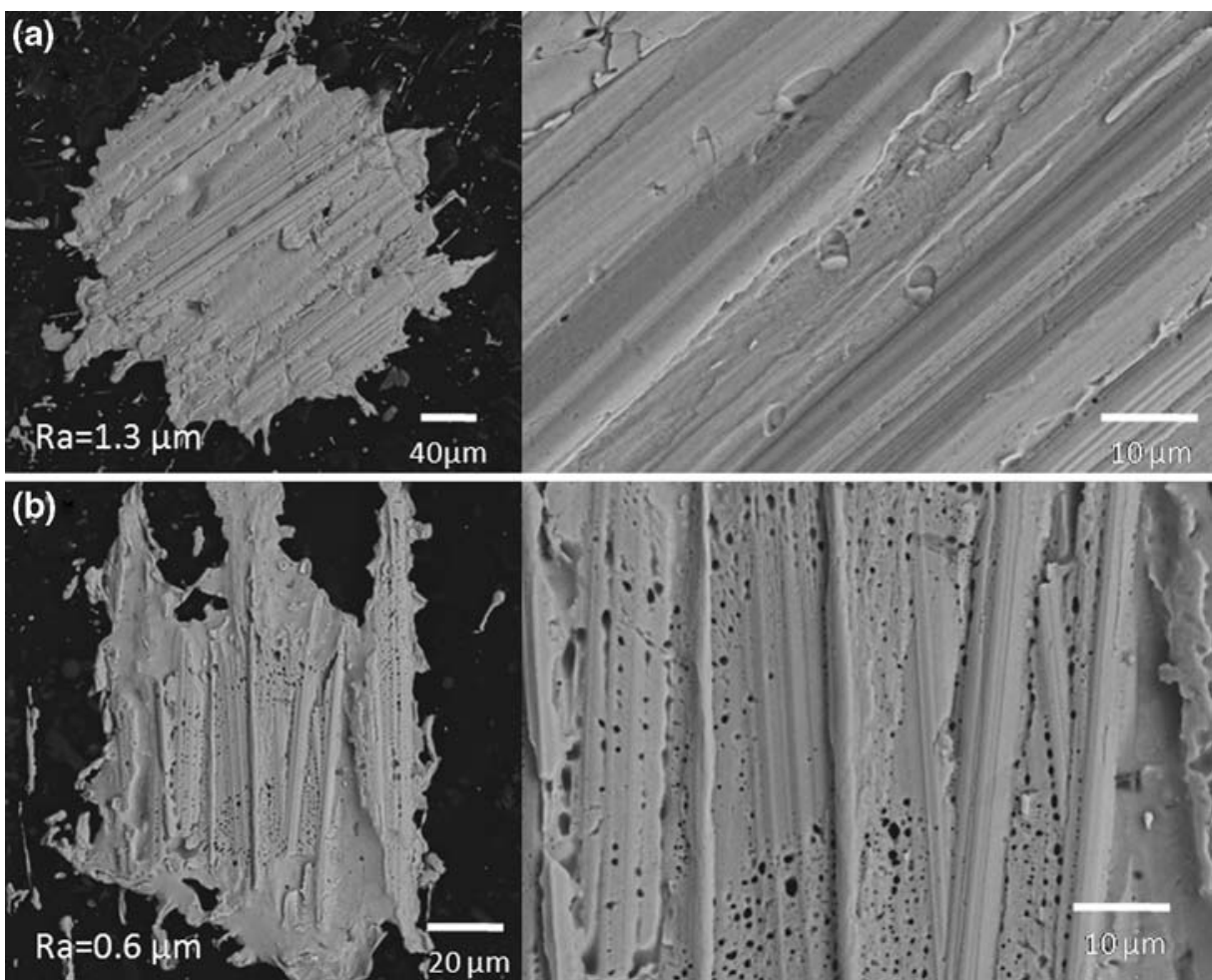

Fig. 7 SEM of splats impacted on rough surfaces
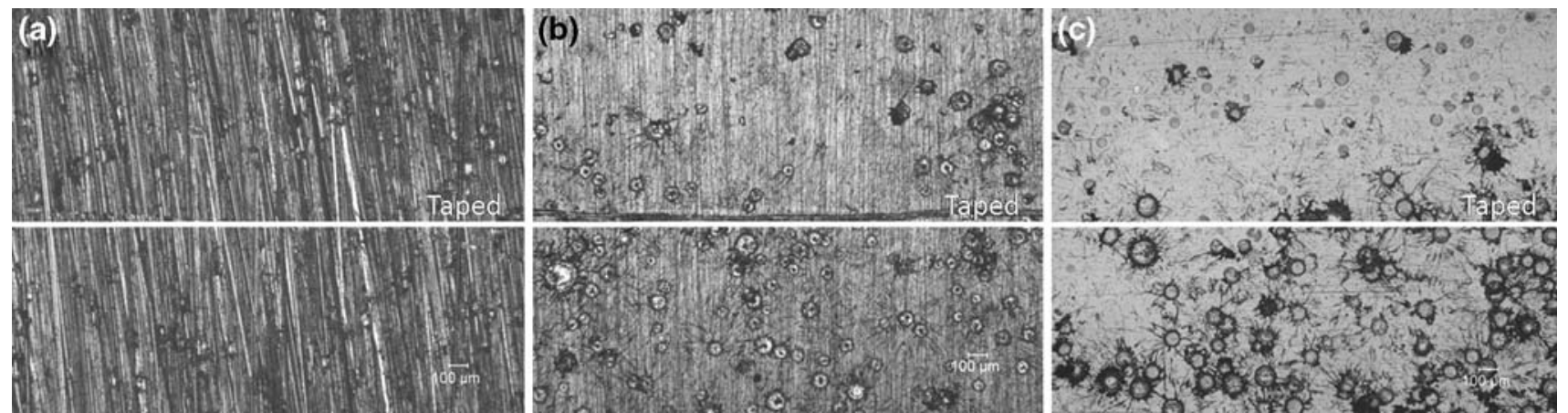

Fig. 8 Optical micrographs of splat pull-off experiments from SS substrates of different roughness: (a) $R_{\mathrm{A}}=1.3 \mu \mathrm{m},(\mathrm{b}) R_{\mathrm{A}}=0.6 \mu \mathrm{m}$, and (c) polished 


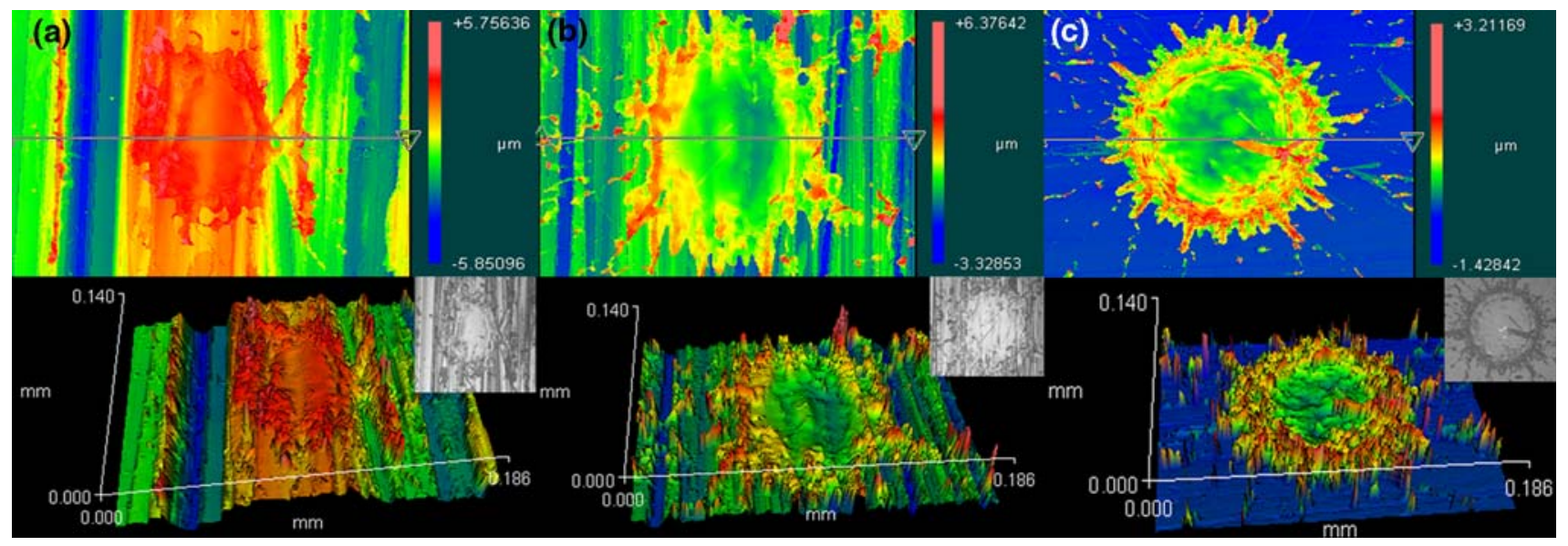

Fig. 9 Scanning white light interferometry (Zygo) images of splats on substrates of different roughness: (a) $R_{\mathrm{A}}=1.3 \mu \mathrm{m},(\mathrm{b}) R_{\mathrm{A}}=0.6$ $\mu \mathrm{m}$, and (c) polished
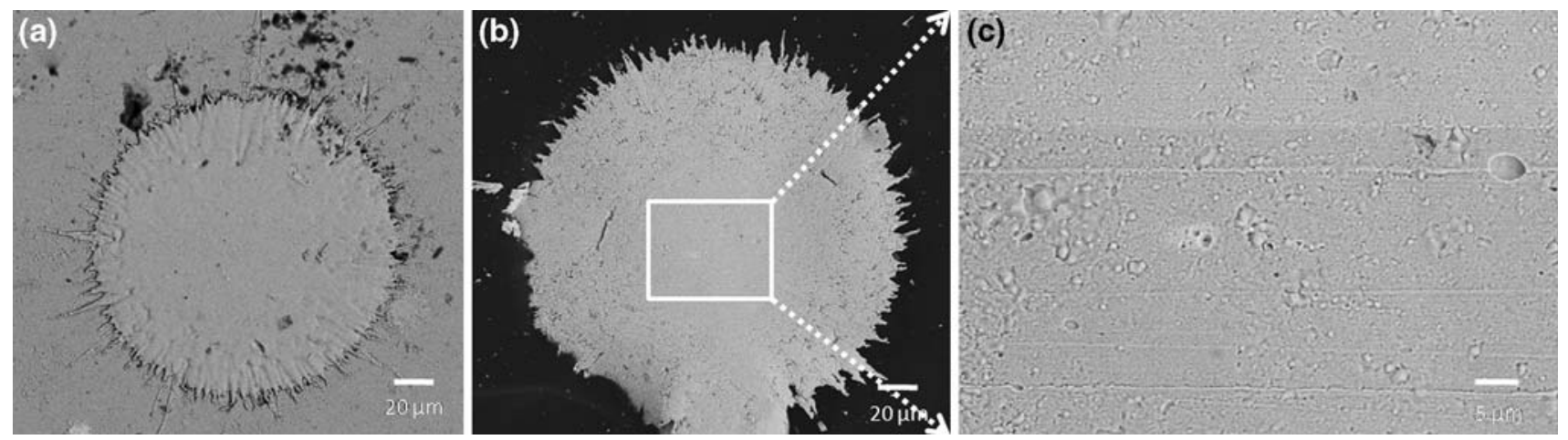

Fig. 10 VPS Ni splats on steel substrates (Ref 22): (a) top, (b) underside, and (c) higher magnification

60-grit substrate very few of the splats have been removed, yet for the polished substrate nearly all have been removed (120 grit falls between the two cases). These results suggest that bonding is more effective on the rougher substrates, and we submit this is at least in part due to the increased bonding area, uninterrupted by bubbles/pores. It has been observed that, in APS on flat substrates, splats curl up (Ref 8) around their edges, due to quenching (Ref 6) or liquid flow on entrapped gas (Ref 35). This is not seen on rough substrates, and fracture mechanics arguments could be made to support the improved adhesion. Consider a splat of diameter $D$ on a substrate, with curl-up length of $L$ on the outside, being pulled up with some average stress $\sigma$. If $L \ll 0.1 D$, the stress intensity factor $K_{\mathrm{I}}$ at the end of the curl-up is of order $K_{\mathrm{I}}=\sigma \sqrt{\pi L}$. A splat on a rough substrate would ostensibly have a much lower $L$ and a higher adhesion. Our experimental observations counter the argument that this would be dominant. First, the mechanism of curl-up would tend to occur on flat or near-flat substrates; there should be little difference in adhesion between splats on substrates of different roughness of the order of particle diameter. Second, the pull-off stress required to lift off the splats from flat substrates was of order MPa (see "Materials and Methods"). In addition, the curling up region $L$ was approximately $10-20 \mu \mathrm{m}$. Using the above equation, this would calculate an interfacial fracture toughness of $0.01(\mathrm{MPa}-\mathrm{m})^{0.5}$, which is far below that expected for a metal-metal bond. Thus, the bubbles/pores affect the intrinsic bonding significantly, both via decrease of contact area and perhaps by affecting heat flux, as suggested by Fukumoto et al. (Ref 4) for pores caused by gas trapping. In addition, Wroblewski et al. (Ref 36) argued with models that roughness increases heat flow between splat and substrate, improving remelting and hence bonding. Bubbles could presumably provide an additional effect on the heat flow. This requires further study.

An additional point of discussion is the source of the supersaturated gas. Calculations (Ref 17) show that before depressurization, trapped gas has sufficient time to dissolve in the near-interface region of the droplet. However, gas could already be dissolved in the liquid droplet before impact, either from the solid powder source or due to dissolution in flight. Literature shows that interdiffusion coefficient $(D)$ of oxygen and nitrogen in liquid metals at their melting temperature is of order $10^{-9}-10^{-8} \mathrm{~m}^{2} / \mathrm{s}$ 
(Ref 37), and the diffusivity of hydrogen can be of higher order, $10^{-7} \mathrm{~m}^{2} / \mathrm{s}(\operatorname{Ref} 37,38)$. With the equation $x=(D t)^{1 / 2}$, the gas diffusion length can be estimated, in other words, we can get an idea of how far into the droplet the gas can travel via simple diffusion. Calculation shows that in $10^{-3} \mathrm{~s}$, the gas diffusion length $x$ ranges from 3 to $10 \mu \mathrm{m}$ (for $D=10^{-8}-10^{-7} \mathrm{~m}^{2} / \mathrm{s}$ ) in flight, not considering fluid mixing, oxidation, etc., providing sufficient time for dissolution. Thus, upon impact, the local high pressure creates a solubility gradient and dissolved gas will diffuse to the high pressure region, and depressurization leads to supersaturation. Figure 10 shows the underside of VPS Ni splats, and no pores are observed. This would indicate the first argument is most applicable in the experiments described in this article.

It is not known to what extent other systems exhibit bubble nucleation upon impact. Reactive metals or materials with low gas solubility could exhibit other gas/ liquid responses, affecting nucleation and also splatsubstrate adhesion in different ways. Nevertheless, this phenomenon could play a large role in the porosity, contact, solidification, and adhesion in a number of relevant materials.

\section{Conclusion}

In this study, we have systematically examined the formation of a high density of nanopores on the underside of Ni splats. Experimental observations were favorably compared with models of heterogeneous nucleation. We conclude with the following arguments:

1. Although the phenomenon was shown only for $\mathrm{Ni}$, bubble nucleation and nanopore formation could occur in any system with reasonable gas solubility, as long as the gas does not react.

2. Rough surfaces significantly decrease bubble formation. However, the extent of this decrease has not been quantified. Obviously, impact on pre-existing splats would not lead to such high porosity, but the geometric 'cut-off' is not known at this point.

3. If controlled, this phenomenon provides a potential method for the fabrication of useful nanoporous surfaces using TS.

4. Although perhaps not the sole mechanism, bubble nucleation likely has an important role in the connection between substrate roughening and TS coating adhesion.

5. This phenomenon is not fully understood; multiphysics modeling and more experiments are needed.

\section{Acknowledgments}

MQ was supported under NSF grant GOALI-FRG (Ceramics). AG was supported under NSF Career CMS 0449268. V. Srinivasan and J. Colmenares helped with the splat deposition. J. Quinn helped with the SEM imaging. The authors thank H. Herman, S. Sampath, R. Neiser, C. Moreau, H. Zhang, M. Gevelber, and A. Goland for helpful discussions.

\section{Open Access}

This article is distributed under the terms of the Creative Commons Attribution Noncommercial License which permits any noncommercial use, distribution, and reproduction in any medium, provided the original author(s) and source are credited.

\section{References}

1. P. Gougeon and C. Moreau, Simultaneous Independent Measurement of Splat Diameter and Cooling Time During Impact on a Substrate of Plasma-Sprayed Molybdenum Particles, J. Therm. Spray Technol., 2001, 10(1), p 76-82

2. P. Fauchais, M. Fukumoto, A. Vardelle, and M. Vardelle, Knowledge Concerning Splat Formation: An Invited Review, J. Therm. Spray Technol., 2004, 13(3), p 337-360

3. S. Sampath, Rapid Solidification and Microstructure Development During Plasma Spray Deposition, J. Therm. Spray Technol., 1996, 5, p 445-456

4. M. Fukumoto, E. Nishioka, and T. Matsubara, Flattening and Solidification Behavior of a Metal Droplet on a Flat Substrate Surface Held at Various Temperatures, Surf. Coat. Technol., 1999, 120, p 131-137

5. A. McDonald, M. Lamontagne, S. Chandra, and C. Moreau, Photographing Impact of Plasma-Sprayed Particles on Metal Substrates, J. Therm. Spray Technol., 2006, 15(4), p 708-716

6. H. Zhang, X.Y. Wang, L.L. Zheng, and X.Y. Jiang, Studies of Splat Morphology and Rapid Solidification During Thermal Spraying, Int. J. Heat Mass Transf., 2001, 44(24), p 4579-4592

7. H.B. Parizi, L. Rosenzweig, J. Mostaghimi, S. Chandra, T. Coyle, H. Salimi, L. Pershin, A. McDonald, and C. Moreau, Numerical Simulation of Droplet Impact on Patterned Surfaces, J. Therm. Spray Technol., 2007, 16(5-6), p 713-721

8. M. Xue, S. Chandra, and J. Mostaghimi, Investigation of Splat Curling up in Thermal Spray Coatings, J. Therm. Spray Technol., 2006, 15(4), p 531-536

9. H. Liu, E.J. Lavernia, and R.H. Rangel, Modeling of Molten Droplet Impingement on a Non-Flat Surface, Acta Metall. Mater., 1995, 43(5), p 2053-2072

10. T. Chraska and A.H. King, Transmission Electron Microscopy Study of Rapid Solidification of Plasma Sprayed Zirconia - Part Ii. Interfaces and Subsequent Splat Solidification, Thin Solid Films, 2001, 397(1-2), p 40-48

11. S. Deshpande, A. Kulkarni, S. Sampath, and H. Herman, Application of Image Analysis for Characterization of Porosity in Thermal Spray Coatings and Correlation with Small Angle Neutron Scattering, Surf. Coat. Technol., 2004, 187, p 6-16

12. S. Polarz and B. Smarsly, Nanoporous Materials, J. Nanosci. Nanotechnol., 2002, 2(6), p 581-612

13. S. Zhang, D. Sun, Y. Fu, and H. Du, Recent Advances of Superhard Nanocomposite Coatings: A Review, Surf. Coat. Technol., 2003, 167(2-3), p 113-119

14. C.L. Tien and G. Chen, Challenges in Microscale Conductive and Radiative Heat Transfer, J. Heat Transf. Trans. ASME, 1994, 116(4), p 799-807

15. R. Yang, G. Chen, and M.S. Dresselhaus, Thermal Conductivity Modeling of Core-Shell and Tubular Nanowires, Nano Lett., 2005, 5(6), p 1111-1115

16. Y.M. Chiang, D.P. Birnie, and W.D. Kingery, Physical Ceramics: Principles for Ceramic Science and Engineering, Har/Disk edn., Wiley, Hoboken, NJ, 1996 
17. M. Qu, Y. Wu, V. Srinivasan, and A. Gouldstone, Observations of Nanoporous Foam Arising from Impact and Rapid Solidification of Molten Ni Droplets, Appl. Phys. Lett., 2007, 90(25), p 254101

18. A. Toramaru, Vesiculation Process and Bubble Size Distributions in Ascending Magmas with Constant Velocities, J. Geophys. Res., 1989, 94(B12), p 17523-17542

19. A. Toramaru, Numerical Study of Nucleation and Growth of Bubbles in Viscous Magmas, J. Geophys. Res., 1995, 100, p 1913 1931

20. G. Qian, T. Nakamura, C.C. Berndt, and S. Leigh, Tensile Toughness Test and High Temperature Fracture Analysis of Thermal Barrier Coatings, Acta Mater., 1997, 45(4), p 1767-1784

21. C.J. Li and J.L. Li, Evaporated-Gas-Induced Splashing Model for Splat Formation During Plasma Spraying, Surf. Coat. Technol., 2004, 184(1), p 13-23

22. L. Li, A. Gouldstone, and S. Sampath, Intrinsic Properties of Thermal Sprayed Single Splats on Substrate, Thermal Spray Solutions: Advances in Technology and Application (ITSC 2004) (Osaka, Japan), Electronic Proceedings, 2004

23. C.K. Shield, C.W. French, and E. Milde, The Effect of Adhesive Type on the Bond of NSM Tape to Concrete, ACI SP230: 7th International Symposium on Fiber-Reinforced Polymer (FRP) Reinforcement for Concrete Structures, American Concrete Institute, November 2005, p 355-372

24. R.S.J. Sparks, The Dynamics of Bubble Formation and Growth in Magmas: A Review and Analysis, J. Volcanol. Geotherm. Res., 1978, 3, p 1-37

25. H.M. Gonnermann and M. Manga, The Fluid Mechanics Inside a Volcano, Annu. Rev. Fluid Mech., 2007, 39, p 321-356

26. C.J. Li and J.L. Li, Transient Contact Pressure During Flattening of Thermal Spray Droplet and Its Effect on Splat Formation, J. Therm. Spray Technol., 2004, 13, p 229-238
27. A.F. Mills, Basic Heat and Mass Transfer, 2nd ed. Series, Prentice Hall, Upper Saddler River, 1999

28. S. Sauerland, G. Lohofer, and I. Egry, Surface Tension Measurements on Levitated Liquid Metal Drops, J. Non-Cryst. Solids, 1993, 156-158, p 833-836

29. M. Chen, C. Yang, and Z. Guo, A Monte Carlo Simulation on Surface Tension of Liquid Nickel, Mater. Sci. Eng. A, 2000, 292, p 203-206

30. C.A. Schuh, Nanoindentation Studies of Materials, Mater. Today, 2006, 9(5), p 32-40

31. L. Li, X.Y. Wang, G. Wei, A. Vaidya, H. Zhang, and S. Sampath, Substrate Melting During Thermal Spray Splat Quenching, Thin Solid Films, 2004, 468(1-2), p 113-119

32. B.C. Earls, Cavitation and Bubble Dynamics, Oxford University Press, Oxford, UK, 1995

33. N.H. March, Liquid Metals, Cambridge University Press, Cambridge, UK, 2005

34. M. Raessi, J. Mostaghimi, and M. Bussmann, Effect of Surface Roughness on Splat Shapes in the Plasma Spray Coating Process, Thin Solid Films, 2005, 506-507, p 133-135

35. D.E. Wroblewski, R. Khare, and M. Gevelber, Solidification Modeling of Plasma Sprayed TBC: Analysis of Remelt and Multiple Length Scales of Rough Substrates, J. Therm. Spray Technol., 2002, 11(2), p 266-275

36. M. Fukumoto, Y. Huang, and M. Ohwatari, Flattening Mechanism in Thermal Sprayed Particle Impinging on a Flat Surface, Thermal Spray, Meeting the Challenge of the 21st Century, ASM International, 1998, p 401-407

37. P. Protopapas and N.A.D. Parlee, Theory of Transport in Liquid Metals IV. Calculation of Interdiffusion Coefficients of Gases in Metals, High Temp. Sci., 1976, 8, p 141-165

38. T. Iida and R.I.L. Guthrie, The Physical Properties of Liquid Metals, Oxford University Press, Oxford, UK, 1993 